\title{
A Chemical and Morphological Study of Diesel Injector Nozzle Deposits - Insights into their Formation and Growth Mechanisms
}

\author{
Nicholas J. Rounthwaite and Rod Williams \\ Shell Global Solutions (UK) \\ Catriona McGivery, Jun Jiang, Finn Giulliani, and Ben Britton \\ Imperial College
}

\begin{abstract}
Modern diesel passenger car technology continues to develop rapidly in response to demanding emissions, performance, refinement, cost and fuel efficiency requirements. This has included the implementation of high pressure common rail fuel systems employing high precision injectors with complex injection strategies, higher hydraulic efficiency injector nozzles and in some cases $<100 \mu \mathrm{m}$ nozzle hole diameters. With the trend towards lower diameter diesel injector nozzle holes and reduced cleaning through cavitation with higher hydraulic efficiency nozzles, it is increasingly important to focus on understanding the mechanism of diesel injector nozzle deposit formation and growth. In this study such deposits were analysed by cross-sectioning the diesel injector along the length of the nozzle hole enabling in-depth analysis of deposit morphology and composition change from the inlet to the outlet, using state-of-the-art electron microscopy techniques. Deposits produced in the injector nozzles of the industry standard fouling test (CEC F-98-08 DW10B bench engine) were compared with those formed in a vehicle driven on a chassis dynamometer, using a drive cycle more representative of real world vehicle conditions, to explore the effects of differing drive cycles and engine technologies. Fouling in all tests was accelerated with the addition of 1ppm zinc neodecanoate, as specified in the CEC DW10B test. This in-depth characterisation revealed a complex multi-layered system of deposits inside the diesel injector nozzle. Through analysing these layers the mechanisms enabling the initial deposit formation and growth can be postulated.
\end{abstract}

CITATION: Rounthwaite, N., Williams, R., McGivery, C., Jiang, J. et al., "A Chemical and Morphological Study of Diesel Injector Nozzle Deposits - Insights into their Formation and Growth Mechanisms," SAE Int. J. Fuels Lubr. 10(1):2017, doi:10.4271/2017-01-0798.

\section{INTRODUCTION}

Direct injection fuel equipment has been developed to allow greater control of engine emissions and fuel economy whilst delivering more power and refinement. As fuel injection equipment has technologically advanced, injector nozzle holes have become smaller to improve the atomisation of the diesel spray. This requires increased control of the fuel injection events and delivery of diesel to the combustion chamber. To maintain this control, it is prudent to use fuels which have been formulated to prevent deposit build up inside injector holes [1]].

The industry standard CEC F-98-08 DW10B bench engine test is a controlled and reproducible method that can achieve significant fouling within hours, making it a practical technique for deposit studies. It was introduced to demonstrate and measure the detrimental effects of injector nozzle deposits on engine performance in common rail engines, specifically engine power. Such deposits restrict and disrupt the flow of fuel through the injector, preventing optimal engine operation. A great number of DW10B injector fouling tests have been reported on in both regular and scientific literature [ $\underline{2}][\underline{3}]$ [4] and yet little is known about the composition and distribution of deposits forming inside the injectors. This is primarily due to the inaccessibility of the deposits forming in the narrow nozzles holes, which can be accessed only by careful sectioning. As the diameter of injector nozzle holes continues to reduce with optimisation of modern fuel injection equipment [5] , the constriction effect produced by layers of deposit formation is predicted to increase; every micron of deposit thickness will create a proportionally larger constriction on the decreasing cross-sectional area of an injector nozzle hole.

Zinc neodecanoate is added to DW10B test fuel to accelerate fouling and produce a consistent, reliable and repeatable fouling response. Similarly fouling accelerants have been applied to other test procedures designed to be more representative of real world conditions in terms of vehicles and drive cycle, thus providing alternative testing platforms with which to rate deposit formation and control characteristics of fuels and additives. Additionally, fouling tests across a range of vehicles have shown the potential for injector nozzle deposits to detrimentally effect BSFC in chassis dynamometer tests [] []].

Previous examination of sectioned minisac type diesel injectors indicated that deposits range in composition, depending on the temperature at which the deposit formed []]. In analysis of a 
cross-sectioned diesel injector from a medium-duty truck engine, Tang et al. showed the deposit composition changed through the cross-section; in particular zinc appeared to be concentrated close to the metal surface of the nozzle and the deposit became more carbonaceous away from the metal interface as it grew thicker [9]. Variation in chemical composition through the deposit indicates that the deposit may form an initiation layer followed by a thicker secondary layer on top, in a growth mechanism which might not be uniform across the length of the injector nozzle.

Building on these previous insights, in the present study diesel injectors were sectioned and analysed to explore the reasons for non-uniform chemistries and morphologies along the injector, allowing for deposit formation and growth mechanisms to be postulated. Improved understanding of these mechanisms enhances the robustness of deposit formation theories and highlights key factors which are instrumental to deposit formation and growth. This study also allowed comparison between the deposits formed in the CEC DW10B test, and chassis dynamometer testing using a lower duty test cycle and a vehicle containing "in market" Fuel Injection Equipment (FIE) technologies, with no modifications to the engine to accommodate its operation on a test bench.

\section{EXPERIMENTAL}

\section{Sources of Injectors}

Three sets of diesel injectors run under different test conditions were used for this study:

The first set of injectors were sourced from a completed 32 hour DW10B dirty up (DU) engine test, using CEC B0 reference fuel containing $1 \mathrm{mg} / \mathrm{kg}$ zinc (from neodecanoate) and Valve Covered Orifice (VCO) type injectors, as specified in the CEC F-98-08 test method.

Sets of injectors from an unmodified European specification Euro 5 diesel vehicle, featuring minisac nozzles, were obtained for this study. This vehicle was driven on a chassis dynamometer (CD) following a test procedure designed to evaluate fouling in vehicles [6]. The test cycle employed on the $\mathrm{CD}$ was developed to be more representative of driving conditions found in real vehicle operation than that specified in the DW10B engine test. Such additional tests are important as they demonstrate the full capabilities of deposit control additive options, increasing the confidence that an additive package will work across a range of conditions. The vehicle was subjected to two different tests; firstly a "dirty-up" (DU) test using CEC B0 reference fuel blended to contain $1 \mathrm{mg} / \mathrm{kg}$ zinc from neodecanoate. Secondly, replacement injectors were installed and a "keep-clean" (KC) test was performed, using CEC B0 reference fuel containing the same zinc component and a diesel deposit control additive formulated at a concentration designed to prevent major deposit build up. From this point onwards injectors from each test will be labelled according to the abbreviations detailed in Table 1.

In both the DW10B DU and the CD DU tests substantial power losses ( $\geq 5 \%$ ) attributed to injector nozzle fouling were observed, whilst the $\mathrm{CD} \mathrm{KC}$ vehicle lost very little power. Figure 1 demonstrates the change in power across each test. Breaks in the power curves produced during $\mathrm{CD}$ testing are points where the diesel particulate filter regenerated, an additional complication of testing a modern car from the market. Data generated during actual regeneration has been omitted.

Table 1. Description of the tests that injectors had undergone for this study

\begin{tabular}{|l|l|l|}
\hline \multicolumn{1}{|c|}{$\begin{array}{c}\text { Abbreviated } \\
\text { injector name }\end{array}$} & \multicolumn{1}{|c|}{ Test } & \multicolumn{1}{|c|}{ Fuel } \\
\hline DW10B DU & CEC DW10B dirty up test & CEC B0 + zinc \\
\hline CD DU & CD dirty up test & CEC B0 + zinc \\
\hline CD KC & $\begin{array}{l}\text { CD keep clean test run with } \\
\text { deposit control additive }\end{array}$ & $\begin{array}{l}\text { CEC BO + zinc }+ \\
\text { deposit control additive }\end{array}$ \\
\hline
\end{tabular}

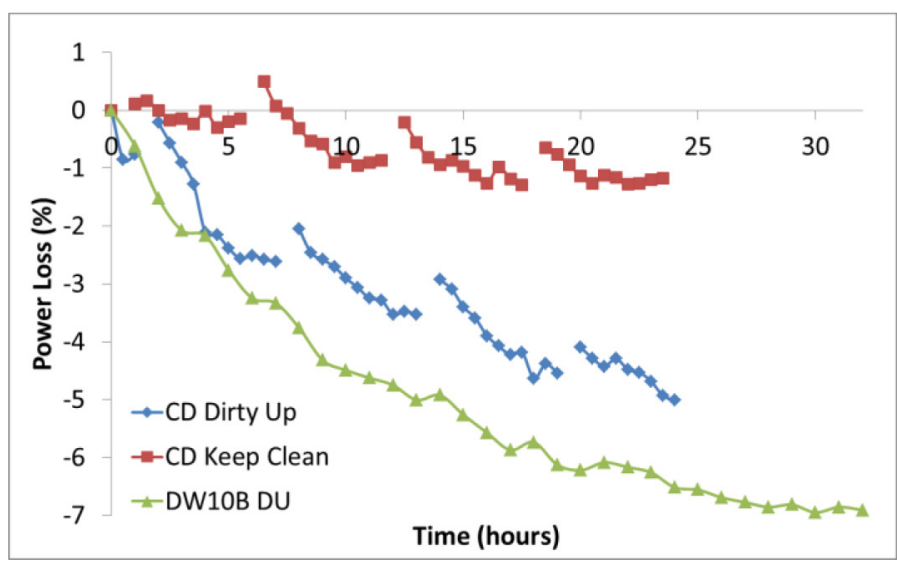

Figure 1. Power loss associated with injector fouling from each test.

\section{Sectioning of Injectors}

Injectors were removed from each engine after testing and carefully cross-sectioned to expose the extent of deposit formation in the nozzle hole, needle seat and sac areas. Sectioning was performed without cutting fluid to minimize disturbance to the deposits inside the injector nozzles. Where possible residual cutting swarf was removed with compressed air. Some residual fragments of steel remained and can be observed in the images.

\section{Analysis Methods}

Scanning Electron Microscopy (SEM) was used to image the cross-sectioned injector nozzles. For this work an FEI Quanta 650F Field Emission Gun SEM (FEG-SEM) was used, equipped with a secondary electron detector and operated at $10 \mathrm{kV}$ and $20 \mathrm{kV}$. Features in the region of $0.5 \mu \mathrm{m}-50 \mathrm{~mm}$ are usually studied using this method. By combining SEM with Energy Dispersive X-Ray Spectroscopy (EDS), site specific chemical analysis can be obtained for regions of interest. This is a powerful technique allowing most elements and their location at the sample surface to be identified. With the introduction of new state of the art detectors it is now possible to identify elements with atomic numbers as low as carbon, which is necessary for this work. The EDS presented here was carried out using a Bruker XFlash®6 with Quantax 800 . 
EDS data cannot be quantified absolutely in these types of samples due to the roughness of the surfaces being studied. However, it is possible to collect and process maps in a semiquantitative manner to show relative trends in compositional variation and location of particular elements on the sample. The EDS maps produced have a colour assigned to each element and the intensity of the colour is an indication of the relative composition. The depth of sample from which X-rays are generated is dependent on the incident energy of the electron beam which is controlled by the operating voltage. If a higher operating voltage is used the electrons have more energy and so penetrate further. The emitted $\mathrm{x}$-rays therefore originate from much deeper in the sample, not just the surface; when a lower operating voltage is used the chemical composition nearer to the surface of the sample is probed. This needs to be taken into consideration when investigating injectors because of the multilayer structure of the steel and deposition layers. There is also a trade-off between the depth being measured chemically and the element being studied - if the incident energy is too low, although more of the top layer of deposit may be being probed, only information about low atomic number elements will be obtained. In this research, to balance these two opposing requirements accelerating voltages of 10 and $20 \mathrm{kV}$ were used for all data.

\section{RESULTS}

\section{Overview of Sectioned Injectors}

Once sectioned an exposed nozzle hole of each injector was examined along its entire length (Figure 2). As expected, noticeable fouling was observed along the injector nozzle holes taken from the engines run on pro-fouling fuel and which experienced power loss (DW10B DU and CD DU tests). A clear deposit severity gradient was apparent along the nozzle holes, as deposit thickness varied from sub-micron size close to the inlet to more severe, $>10 \mu \mathrm{m}$ thick, deposits at the outlet. This coincided with a general transition in morphology from a mostly smooth layer of deposit at the injector nozzle hole inlet to a rough deposit at the outlet. The exception to this was at the sac/inlet interface, where some thicker, moderately rough deposits were observed. Considering the full length of the nozzle hole, it can be seen that the deposit build up was less regular in the CD DU injector than in the DW10B DU injector.

Other than a few small flakes of material, mostly steel from the sectioning of the injector, there was no visible deposit in the area of the needle seat of the DW10B injector, with the original machining marks clearly visible (Figure 3a). Figure 3b however highlights a further issue, that of deposit build up in the minisac in real vehicles. These deposits encroached on the nozzle hole inlet, which would be unexpected in the DW10B due to its use of VCO nozzles.
Full length of nozzle

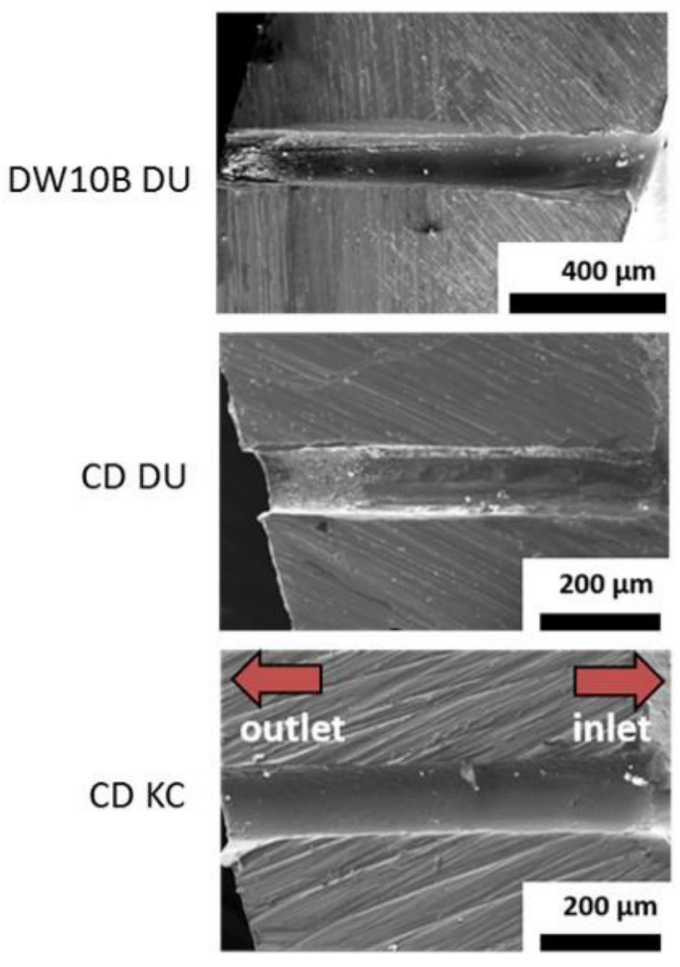

Towards outlet
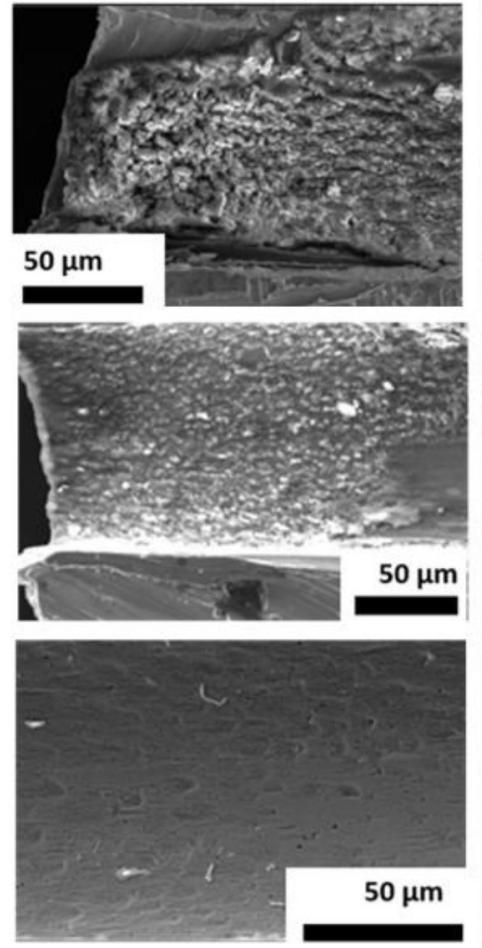

Towards inlet
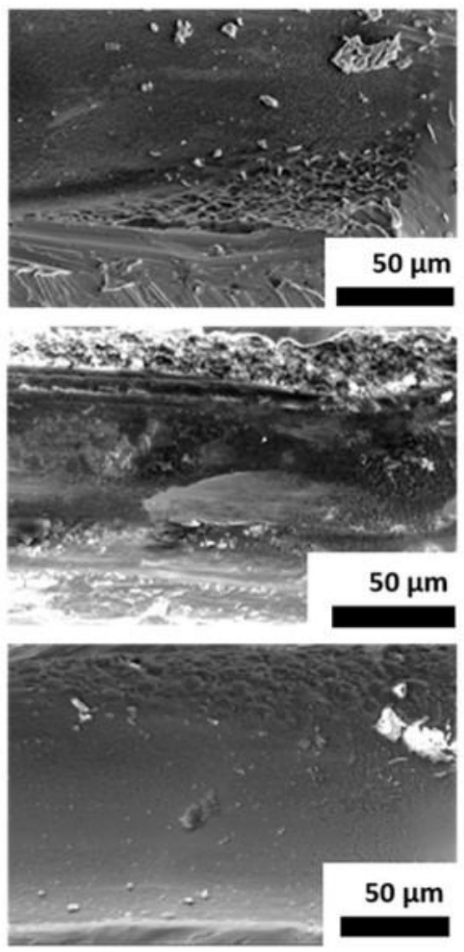

Figure 2. SEM overview of deposit formation across a diesel injector nozzle hole from each test. 

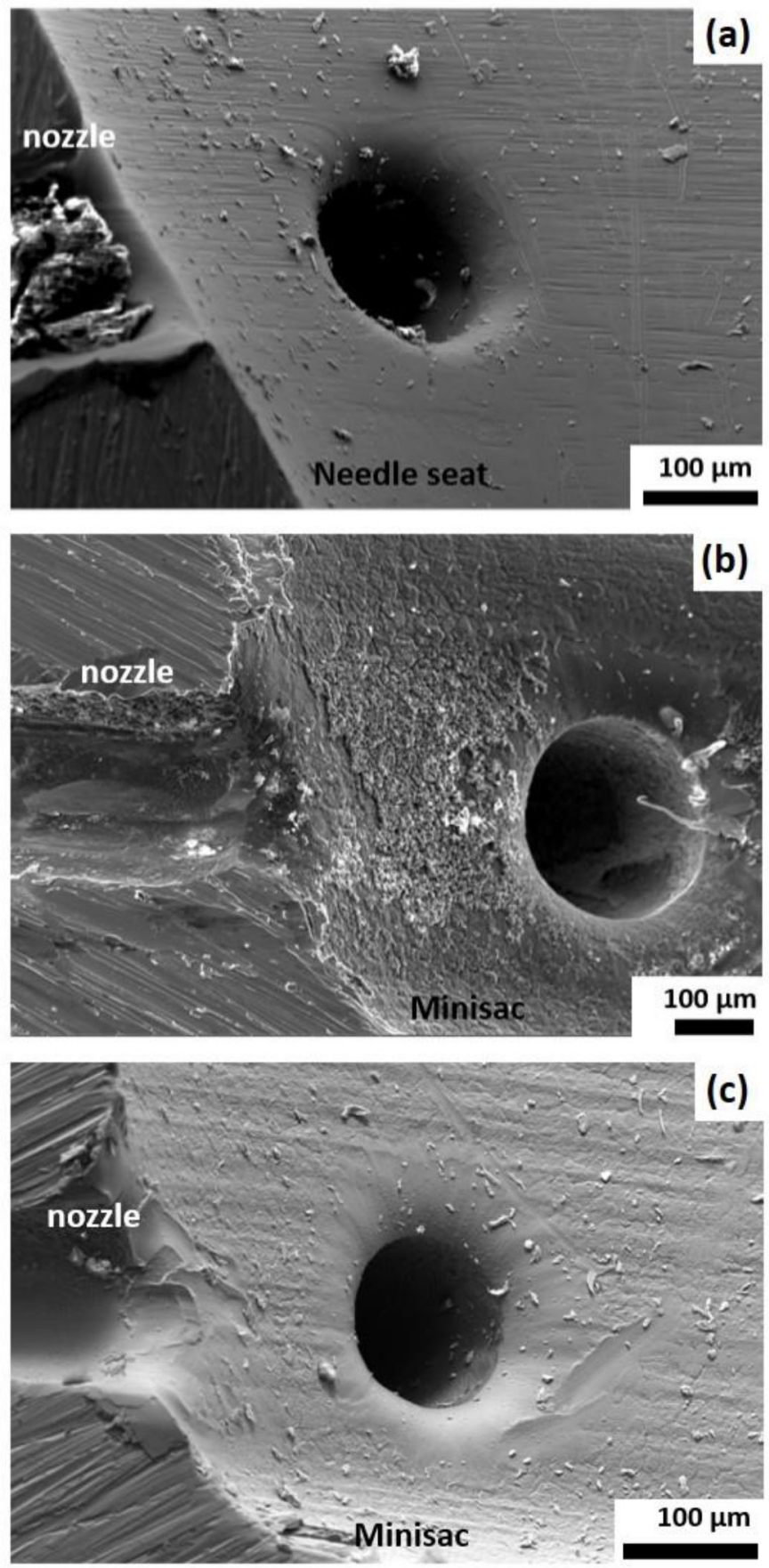

Figure 3. SEM images of the minisac/needle seat area and nozzle inlet for injectors from (a) the DW10B DU test, (b) CD DU test and (c) CD KC test.

Finally the injector taken from the vehicle run on fuel containing deposit controlling additive was observed to contain very little deposit in either the minisac or the nozzle hole, with the original machining marks on the surface of the injector still visible (Figure 2 and Figure 3c). It is noted that the morphology of the underlying steel was different for CD KC and DW10B test samples - the granular topology of the steel is evident in the $\mathrm{CD} \mathrm{KC}$ injector, whereas in the DW10B injector the steel is clearly smoother. This is likely to be due to the abrasive flow machining (honing) employed in the CEC specification for DW10B nozzles used to 
achieve high hydraulic efficiency, low cavitation and therefore increased tendency towards deposit build up. It should be noted that the apparent differences in hole geometry between the vehicle samples (igure 2) are likely to be artefacts of small misalignments of the sectioning with the hole axis. The convergence of the DW10B nozzle hole towards the exit shows hole conicity which is employed to alleviate the vena-contracta caused by cavitation at the hole inlet and thus increase the hydraulic efficiency (discharge coefficient) relative to the size of the exit hole. The DW10B nozzle holes also appeared to be longer than those of the production injector in the CD tests [10].

\section{Deposit Morphology}

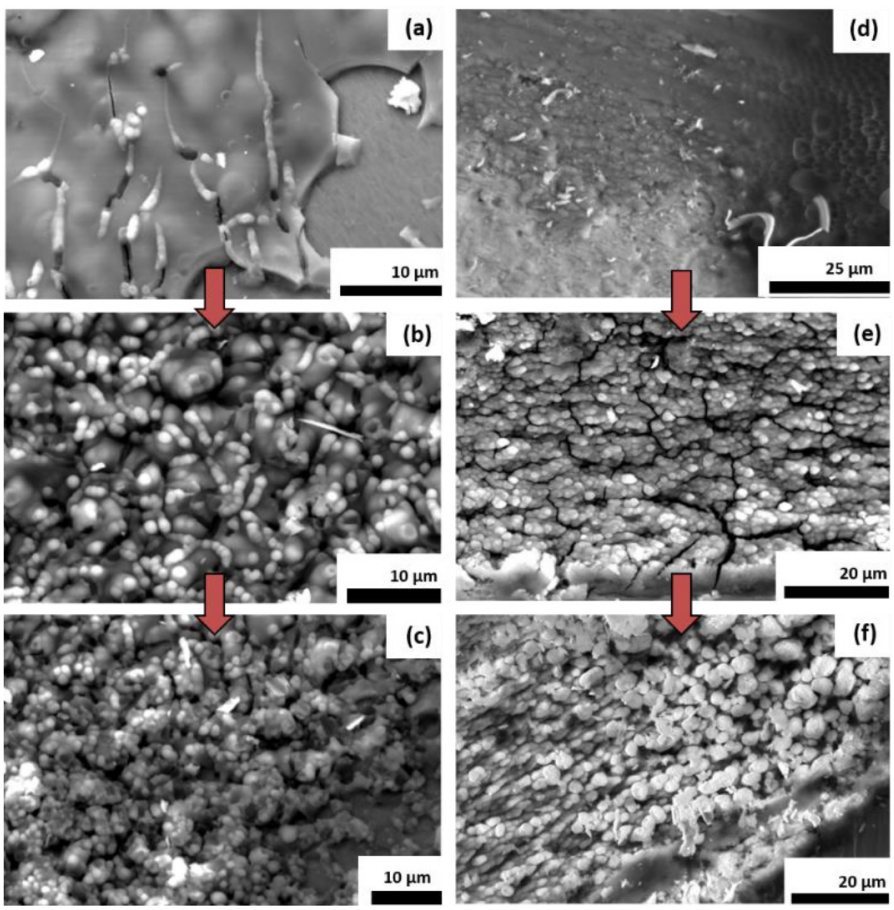

Figure 4. Mechanism of deposit formation: (a) to (c) illustrate the deposit build up in the CD DU injector and (d) to (f) in the DW10B DU injector. Both start as a thin film but in the CD DU test the thin film is seen to crack, creating nucleation sites for a secondary deposit.

For the fouled injectors (CD DU and DW10B DU) presented in Figure 2 there was a general transition of deposit morphology from smooth to rough, progressing from the inlet towards the outlet. Selected areas of deposits from the CD DU tests are shown in Figure 4 (a-c), highlighting this transition. These were taken from different locations within the mini-sac region, where the morphological change was clearest, but are representative of the transition seen in the injector nozzle hole. These images offer a series of snap shots that indicate a deposit growth hierarchy of:
1. The thinnest deposits appeared as a smooth film across the steel surface of the injector.

2. As this film grew in thickness cracks formed.

3. Cracks became initiation sites for globular secondary deposit formation, infilling the cracked layer.

4. Thick areas of deposit grew to form an uneven globular layer.

The periodicity of cracking in Figure 4 (a) is symptomatic of "mud cracking" which is commonly seen in research into thin films [11]. The abrupt edge of the deposit demonstrates how such mud cracks can lead to delamination and loss of deposit, as well as new growth.

In the DW10B DU injectors deposits appeared to grow from a film to bulbous deposits, without the need for new initiation sites (Figure 4 d-f). The mechanism of mud cracks acting as secondary initiation sites was not observed, even when cracking was present (Figure 4 e). In both the CD DU and DW10B DU nozzles the thickness and diameter of these rounded deposits increased towards the outlet of the nozzle.

\section{Deposit Composition}

In addition to the different morphologies observed between the DW10B DU and CD DU tests, caused by deposit hierarchical growth mechanisms, EDS in Figure 5 revealed that the chemical makeup of the deposit also appeared to vary from one fouling test method to the next. Only samples from the dirty up tests are considered as there was insufficient deposit for analysis in the CD KC samples.

\section{DW10B DU}

The EDS of the thick deposit in the DW10B injector nozzle shows a uniform concentration of zinc, i.e. a similar level of colour intensity across the image. The only areas where the zinc signal was weak was a result of the cracks in the surface of the deposit (the darker areas in the map). Carbon and oxygen appear co-located with the zinc across the deposit, producing a reasonably homogeneous deposit. This elemental relationship was consistent across the range of thicknesses of the deposit, from the inlet to the outlet.

\section{DU - Thin Deposit}

The thin film deposits were again homogeneous, consisting of mostly zinc and oxygen and to a lesser extent carbon. The intensity of the carbon map has been enhanced to better show the even distribution, of the element (it was previously dull due to a comparatively low of carbon signal). The purpose of Figure 5 is to show the concentration gradient of an element across a surface, so enhancing the brightness of an image does not affect the interpretation. Although from these maps it appears that the crack regions have higher carbon content, more precise EDS line traces across these regions show that both the carbon and zinc content does not fluctuate much across the crack. 


\section{DU - Thick Deposit}

The regions with thicker bulbous deposits have significant variations in chemical composition. There is a uniform layer of zinc across the whole deposit. On top of this are then thick bulbous centres containing high concentrations of co-located carbon and oxygen. This was confirmed from an elemental line profile of the region which showed a fairly constant $\mathrm{Zn}$ concentration but fluctuations in the $\mathrm{C}$ and $\mathrm{O}$ which match the positions of the bulbous deposit.

An elemental distribution map of the full length of the injector nozzle hole from the CD DU test is shown in Figure 6 to illustrate the variation in deposit over the entire length. It is clear from the high intensity in the iron map that closest to the inlet there is much less deposit build up than at the outlet, where less Fe signal is detected, as it is obscured by thicker deposit growth. From this map the inconsistent morphology of the deposit can also be seen.

Careful inspection of the zinc map suggests that the zinc covers much more of the nozzle surface than carbon or oxygen, reaching into the regions where the Fe signal is at a maximum. The carbon signal increases from inlet to outlet, suggesting that more carbonaceous deposit builds up towards the outlet of the nozzle hole. The zinc signal is also weaker at the outlet of the injector nozzle hole, where the carbon signal becomes more intense. The location of oxygen follows that of carbon, being more prominent in the areas of thicker deposit.

\section{DW10B DU - Thick deposit}

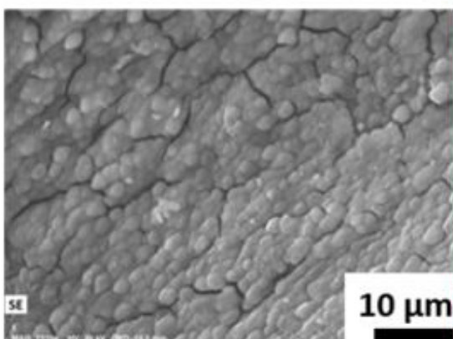

CD DU - Thin deposit
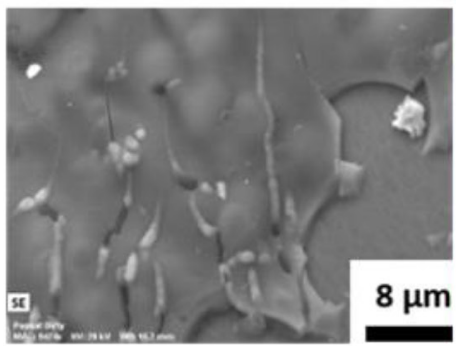

CD DU - Thick deposit
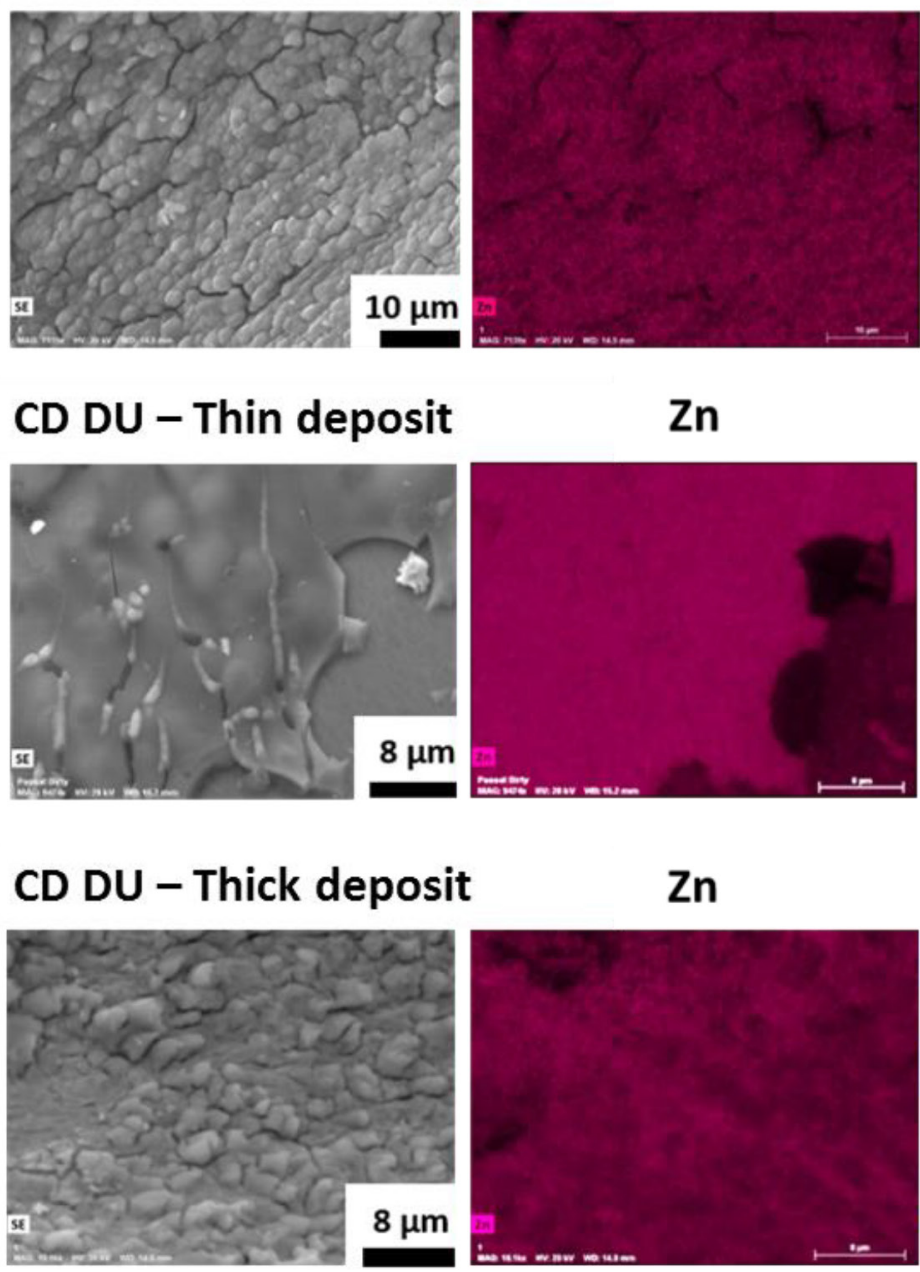

Е
$\mathrm{Zn}$

\section{$\mathrm{Zn}$}

$+$

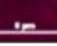

Zn

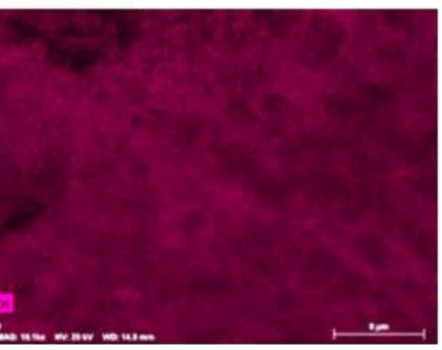

C

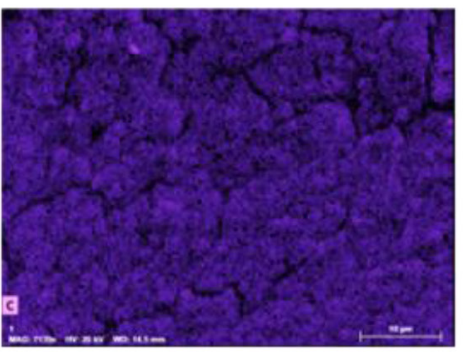

C

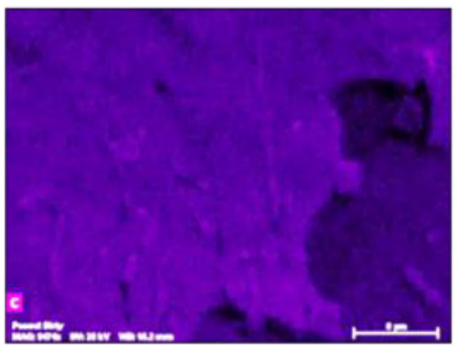

C

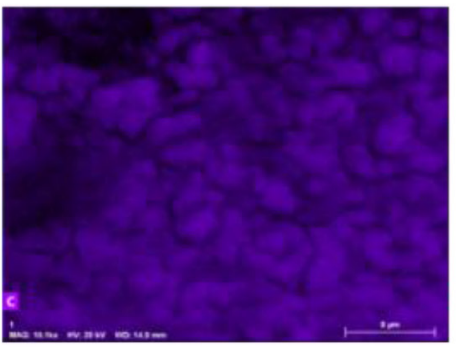

O

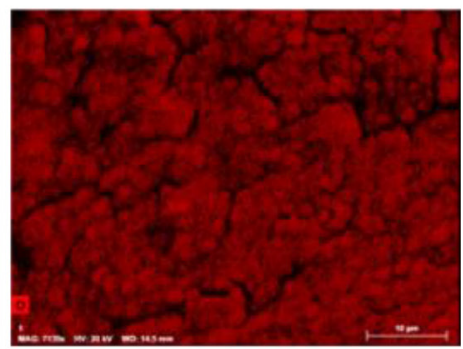

O

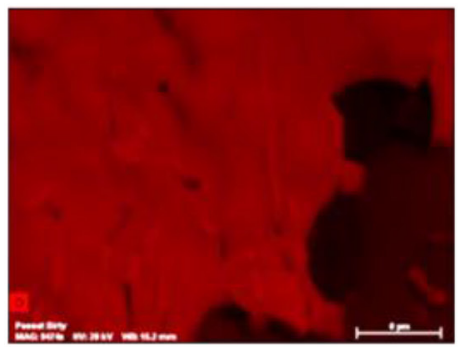

0

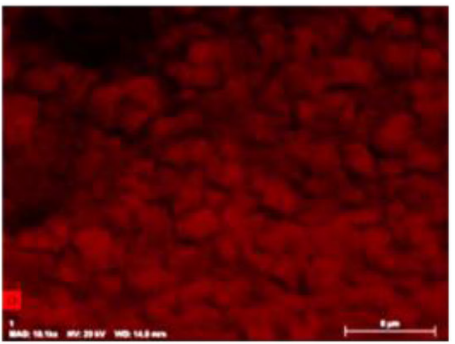

Figure 5. EDS elemental maps of each deposit type. The comparison focusses on $\mathrm{Zn}, \mathrm{C}$ and $\mathrm{O}$ as they constitute the majority of the elements discovered (trace elements were also observed, but are not displayed here). The contrast has been adjusted to show location of the elements. The CD DU - thin deposit has been analysed in the minisac. All other analysis is from the outlet of the injector. 

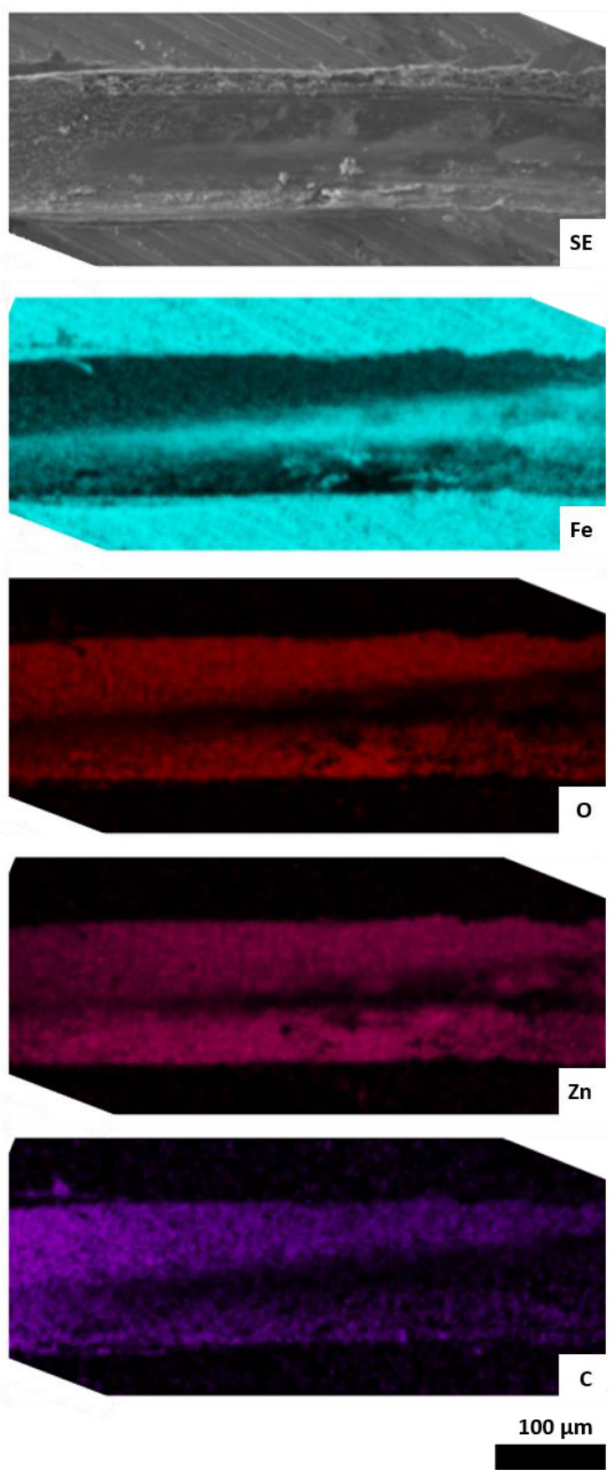

Figure 6. EDX maps of the main deposition elements along a nozzle from the CD DU test (hole outlet is on the left).

\section{Injector Surface Analysis}

EDS of the injector from the CD KC test, where deposit control additive prevented major deposit growth, can also be used to produce insights into deposit initiation. Although there was little visible deposit in the SEM images, elements can be identified in the EDS scans. The grain morphology of the underlying steel clearly stands out in these maps along with local segregation of the chromium towards grain boundaries (Figure 7), revealing a grain size of $5-10 \mu \mathrm{m}$ in this area of the minisac. It is apparent from these EDS maps that zinc has been deposited on the surface of the injector on the same scale as the grain size. Whilst zinc has been deposited on all of the grains, some grains have a higher concentration of deposit present. Results shown are from the minisac for clarity (despite zinc surface layers being observed in the nozzle holes), as damage to the steel grain structure during nozzle hole manufacture has made grain boundary segregation in the nozzle holes less clear.

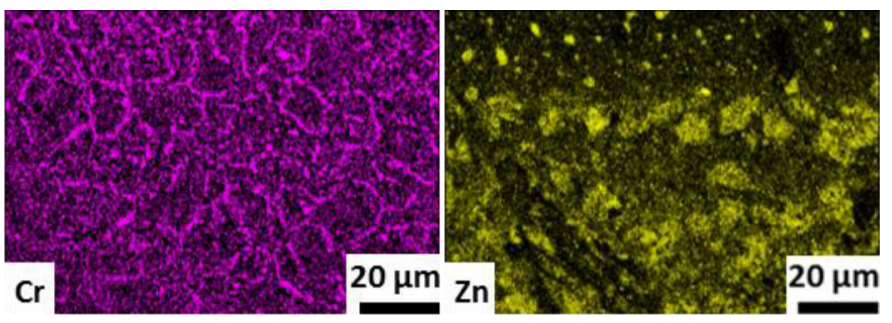

Figure 7. EDS maps of the minisac region of the $\mathrm{CD} \mathrm{KC}$ injector with chromium segregation highlighting the grain structure of the injector steel. Zinc deposits on the surface of the steel are localised towards grain interiors and preferentially located on specific grains.

\section{DISCUSSION}

From the power loss curves of the DW10B DU and CD DU tests it was apparent there could be a difference in the fouling occurring in the diesel injector nozzles. The DW10B DU produced faster and more severe fouling, as would be expected for a test method with injectors and running conditions optimised for the growth of nozzle hole deposits. The CD DU test which was more representative of real world vehicle conditions resulted in significant fouling, leading to power loss, but from the power loss curves alone it is not possible to identify if the rate of injector deposit build up was just slower or if the deposit being produced was fundamentally different.

\section{Deposit Morphology}

In both the DW10B DU and CD DU tests the deposit structure varied from inlet to outlet, with a thin and smoother film at the inlet which progressed towards a rougher and thicker layer at the outlet, adjacent to the combustion chamber.

The deposits are thought to be formed as a remnant of the combustion process, as a result of residual fuel, particulates and vapours, and this would explain why the layers are thicker and more developed towards the outlet, where these components are all readily available $[\underline{8}, \underline{9}]$. Deposition has occurred all the way into the minisac of the CD DU injector. As the deposits in the minisac appear similar to those found in the injector nozzle hole, it is apparent that these fundamental constituents for deposit formation were present across all areas downstream of the injector needle seat. Additionally the high temperatures in the engine, when thermally conducted along the injector, will likely act as an accelerant to deposit formation. It is generally observed that higher engine temperatures increase deposit severity $[\underline{6}, \underline{8}, \underline{9}, \underline{12}]$.

The consistent nature of the deposit topology in both tests (Figure 2) is in spite of different injector designs and fouling test methods indicating similar trends in the formation of deposits in diesel injector nozzles. For deposits of this type, a particular concern is the thickness and extent of these deposits (often extending to $>10 \mu \mathrm{m}$ in thickness) which can form substantial constrictions in nozzle holes of diameters in the order of $100 \mu \mathrm{m}$. This is increasingly important as there is a trend towards use of high hydraulic efficiency nozzles with reduced hole diameters which are more susceptible to power and efficiency losses caused by deposit build up [1ㅜ] . 
Cavitation is known to provide a cleaning effect in the nozzle hole due to the high energy of bubble collapse close to the surface of the injector, which can erode away deposits []ㅡ. The degree of cavitation will be dependent on the internal geometry of each injector design. This bubble collapse is expected to occur between the inlet and the middle of the nozzle hole length - the area where the least and often smoothest deposit was found in this study. However, this deposit distribution could also be affected by the proximity to the combustion chamber as already mentioned. The high hydraulic efficiency DW10B injectors are designed to produce less cavitation so would be less likely to delaminate the thin film deposit from the surface of the injector.

Cavitation could also affect the distribution of deposits through a second mechanism, on the corner of the nozzle hole inlet. In each injector nozzle there was a region of rough deposit formation on the corner of the inlet and the minisac/valve seat of each injector. Here the flow of liquid fuel would be pushed away from the surface of the injector by the cavitation and the formation of a vena contracta [14] (before bubble collapse). This prevents contact with liquid fuel would have carried away the deposit pre-cursors, especially in the deposit control additive containing $\mathrm{CD} \mathrm{KC}$ fuel.

In addition to the deposit formation in the injector nozzle, this paper has highlighted the high level of fouling which can occur in the minisac of an injector, the effects of which should not be experienced in the VCO injector of the DW10B. Such minisac deposits would be difficult to characterize without nozzle sectioning. It is clear that these deposits encroach on the nozzle hole inlet, leading to restriction at the inlet of the nozzle as well as altering the flow of fuel through the injector.

If the conditions in the minisac are representative of those in the nozzle hole of the injector, the formation path of deposits appears very different between tests. The deposits produced in the CD DU tests were reliant on the initial thin film layer, which acted as the initiation site for the formation of thicker deposits. The bulbous deposits appear to have nucleated in the cracks running through the film. It is probable that these cracks formed as the result of differing thermal expansion coefficients between the metal injector and the growing deposits (this results in thermal strains and mud flat cracking). Residual fuel could be trapped in these cracks, providing the reagents for new deposits. After several layers of growth, in the regions where the deposit is more bulbous, it becomes clear that a thicker, interrupted layer of material grows.

In the DW10B injector there was no evidence of cracks in the underlying deposition layers initiating further deposit growth. This is despite the presence of cracks in the deposit.

\section{Deposit Chemistry}

As there is no standard diesel injector design or engine operating conditions from one manufacturer to the next, as well as a multitude of different driving styles, it is important to recognise the possibility of a range of deposit types which could be formed inside an injector nozzle. EDS analysis revealed the deposits found in the DW10B DU and CD DU tests consisted primarily of zinc, oxygen and carbon. However there were differences in the positioning of these elements, and this is likely due to differing formation processes, as indicated in Figure 4 and Figure $\underline{5}$. Both tests achieved accelerated fouling through the introduction of zinc, and yet the mechanism by which zinc enhanced the deposit growth appears to be different. In the DW10B the deposit formed was relatively homogeneous, suggesting that zinc was equally as important in deposit growth from the start to the end of the fouling test.

In the CD DU test the zinc appears to have been important as an initiation layer, to start the deposit growth. Figure 6 showed the thin $(<100 \mathrm{~nm})$ initial layer of zinc deposited across the majority of the injector surface. Then, in some regions, a more carbonaceous deposit grows on top of it, most likely with additional zinc deposition. This is further suggested by the slight decrease in zinc signal at the outlet where the carbon signal is enhanced due to increased deposit build up (clearly a thicker deposit as the Fe signal was minimal). The range in the composition of nozzle deposits, with decreasing concentration of zinc towards the outlet, due to this bulbous more carbonaceous deposit becoming dominant is in agreement with previous observations of sectioned minisac type injectors [] [ [15] .

In the $\mathrm{CD} \mathrm{KC}$ test, there appears to be an equilibrium between near total deposit removal through deposit controlling additive and slight growth on specific steel grains where extremely thin films of zinc have formed. The selectiveness of this film formation is most likely the influence of the surface grain orientations, implying the underlying nozzle may play a role in the formation of the initial layer of deposit. Note that while these deposits can be observed using high resolution electron microscopy techniques, these thin deposits in their current form, as well as the deposit thought to be formed by geometric cavitation at the injector nozzle hole inlet, were too small to have a major impact on fuel flow through the nozzle, as was shown in the power loss curves (Figure 1).

It is unclear which aspect of the testing produced the difference in deposit type from one test to the next. The different engines and test methods would have produced different temperatures in the injectors potentially leading to different deposit formation and growth kinetics. Furthermore, the closure of each nozzle in the DW10B VCO injector versus the constantly open minisac will have led to different mixes of residual fuel and combustion chamber gas from which the deposits can grow. It has been suggested that enhanced diesel injector nozzle fouling through the inclusion of zinc salts in the fuel relies on precipitation of the zinc salt in the hot diesel injector as the primary fouling mechanism $[\underline{8}, \underline{15}]$. The evidence from the sectioned DW10B injector of uniform deposits with consistent zinc content supports this theory. The structure observed in the deposits from the CD DU indicate a more complex system of coking indicating the value of having access to additional test methods to determine the effectiveness of a deposit controlling additive against a range of deposit types.

\section{CONCLUSIONS}

Injector nozzles from DW10B bench engine and real vehicle CD tests have been sectioned to study deposit formation. From bench engine and $\mathrm{CD}$ tests running identical pro-fouling fuels (containing 1ppm zinc) it was found that: -

- In both cases the deposit is predominantly composed of $\mathrm{C}, \mathrm{O}$ and $\mathrm{Zn}$, though the zinc is found in a base layer in the vehicle 
nozzle and homogenously distributed in the engine nozzle indicating differing formation mechanisms.

- In both cases the deposit thickness increases towards the hole outlet due to proximity to the combustion chamber, however there is also a thicker layer of deposit near the hole inlet where the fuel flow detaches from the hole wall interrupting normal fuel flow.

- Deposits form in the mini-sac of the sac type nozzle, but cannot form in the DW10B VCO nozzle.

- In the DW10B a laminar deposit forms and grows in thickness, whereas in the vehicle an initial layer cracks and bulbous secondary deposits form in the cracks.

- $\quad$ Sustained use of a high quality deposit control additive can prevent deposit build up in the mini-sac and nozzle hole except in the region of the hole inlet, however these deposits have little measurable effect on engine performance.

This paper highlights the potential for a range of deposit types that can be produced, with potentially differing mechanisms for formation, both as bulk deposit and as the initial layer. In this case engine technology and test cycles were varied, but fuel composition was kept constant. These changes alone dictated both how and where injector nozzle hole fouling occurred and could ultimately affect how engine performance degrades with injector fouling. Better understanding of such intricate factors necessitates higher resolution microscopy techniques, such as transmission electron techniques, which may in future link macroscopic morphology with the initiation and growth of deposits in these tests.

\section{RECOMMENDATIONS}

A significant proportion of this paper analysed deposits formed in the minisac of the injector, where conditions are likely to be less severe, due to less direct access to hot gas from the combustion chamber than the nozzle hole outlet and potentially less erosion from the surface of the injector by liquid fuel. To comprehensively understand the deposit formation mechanisms involved in deposit initiation it would be necessary to extract nozzles from the early stages of deposit formation tests. This would be achieved by inserting a number of intervals into an engine test at which injectors could be removed for analysis and replaced with a fresh injector.

\section{REFERENCES}

1. Barker, J., Richard, P., Snape, C., and Meredith, W., "Diesel Injector Deposits - An Issue That Has Evolved with Engine Technology," SAE Technical Paper 2011-01-1923, 2011, doi:10.4271/2011-01-1923.

2. Leedham, A., Caprotti, R., Graupner, O., and Klaua, T., "Impact of Fuel Additives on Diesel Injector Deposits," SAE Technical Paper 2004-012935, 2004, doi: $\underline{10.4271 / 2004-01-2935}$.
3. Caprotti, R., Breakspear, A., Graupner, O., Klaua, T. et al., "Diesel Injector Deposits Potential in Future Fueling Systems," SAE Technical Paper 2006-01-3359, 2006, doi: 10.4271/2006-01-3359.

4. Montanaro, A. and Allocca, L., "Impact of the Nozzle Coking on Spray Formation for Diesel Injectors," SAE Technical Paper 2013-01-2546, 2013, doi:10.4271/2013-01-2546.

5. Velaers, A. and de Goede, S., "The Properties and Injector Nozzle Fouling Performance of Neat GTL and GTL/EN590 Diesel Blends in Various Diesel Engines," SAE Int. J. Fuels Lubr. 5(3):1174-1186, 2012, doi:10.4271/2012-01-1692.

6. Williams, R., Smith, A., and Buttery, I., "Formation and Removal of Injector Nozzle Deposits in Modern Diesel Cars," SAE Int. J. Fuels Lubr. 6(1):230-240, 2013, doi:10.4271/2013-01-1684.

7. Smith, A. and Williams, R., "Linking the Physical Manifestation and Performance Effects of Injector Nozzle Deposits in Modern Diesel Engines," SAE Int. J. Fuels Lubr. 8(2):344-357, 2015, doi:10.4271/2015$\underline{01-0892}$.

8. Ikemoto, M., Omae, K., Nakai, K., Ueda, R. et al., "Injection Nozzle Coking Mechanism in Common-rail Diesel Engine," SAE Int. J. Fuels Lubr. 5(1):78-87, 2012, doi:10.4271/2011-01-1818.

9. Tang, J., Pischinger, S., Lamping, M., Körfer, T. et al., "Coking Phenomena in Nozzle Orifices of D1-Diesel Engines," SAE Int. J. Fuels Lubr. 2(1):259-272, 2009, doi:10.4271/2009-01-0837.

10. Caprotti, R., Breakspear, A., Klaua, T., Weiland, P. et al., "RME Behaviour in Current and Future Diesel Fuel FIE's," SAE Technical Paper 2007-01-3982, 2007, doi:10.4271/2007-01-3982.

11. Thouless M. D., "International Conference on Metallurgical Coatings, San Diego, 1989 Some mechanics for the adhesion of thin films," Thin Solid Films, vol. 181, pp. 397-406, 1989/12/10 1989, doi: 10.1016/00406090(89)90508-7.

12. Birgel, A., Ladommatos, N., Aleiferis, P., Zülch, S. et al., "Deposit Formation in the Holes of Diesel Injector Nozzles: A Critical Review," SAE Technical Paper 2008-01-2383, 2008, doi:10.4271/2008-01-2383.

13. Caprotti, R., Bhatti, N., and Balfour, G., "Deposit Control in Modern Diesel Fuel Injection Systems," SAE Int. J. Fuels Lubr. 3(2):901-915, 2010, doi:10.4271/2010-01-2250.

14. Lockett R. D., Liverani L., Thaker D., Jeshani M., and Tait N. P., "The characterisation of diesel nozzle flow using high speed imaging of elastic light scattering," Fuel, vol. 106, pp. 605-616, 2013, doi: 10.1016/j.fuel.2012.10.065. P. Risberg and S.

15. Risberg, P. and Alfredsson, S., "The Effect of Zinc and Other Metal Carboxylates on Nozzle Fouling," SAE Technical Paper 2016-01-0837, 2016, doi: $10.4271 / 2016-01-0837$.

\section{CONTACT INFORMATION}

Nick Rounthwaite nicholas.rounthwaite@shell.com

\section{ACKNOWLEDGMENTS}

The authors would like to thank Neal Morgan for helpful discussions and encouragement.

\section{FUNDING}

This research was performed with financial support of the Shell University Technology Centre (UTC) for Lubricants and Fuels, hosted at Imperial College London.

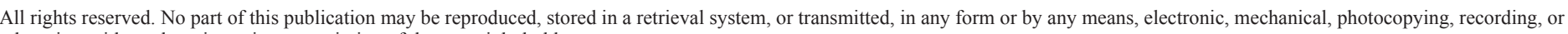
otherwise, without the prior written permission of the copyright holder. 